Pakistan Journal of Social Sciences 7 (2): 143-145, 2010

ISSN: $1683-8831$

(C) Medwell Journals, 2010

\title{
Steps in the Sociotherapeutic Approach to School Discipline: A Human Touch Deviant Control
}

\author{
Felix M.E. Okpilike \\ Department of Educational Administration and Policy Studies, \\ Delta State University, Abraka, Nigeria
}

\begin{abstract}
The study examines the nature of school discipline at the primary and secondary level of education in Nigeria. Discipline is considered an important aspect of school life that promotes effective teaching and learning. Over the years, the Nigerian school system had depended on punishment as the only means of enforcing discipline among the students. It is now known that punishment as a means of correcting offenders though serve as a deterrent has limited effects beyond which it serve no useful purpose. The study therefore argues that punishment as a means of promoting school discipline has become ineffective and should be abandoned. In its place the study proposes the use of more human approach-the-socio-therapeutic technique which attempts a sociological diagnosis of social problems among the students before attempting to proffer solution.
\end{abstract}

$\underline{\text { Key words: Sociotherapeutic approach, school displine, school system, punishment, social problems, Nigeria }}$

\section{INTRODUCTION}

No society had been able to live without regulations. Apparently, the more complex the society, the greater is the need for a detailed description of behavior which are permitted and those which are prescribed. The rules and regulations are designed to make it possible for men to live together and thus enhance the living condition of the individuals. A disciplined society had always been cherished throughout human history. Thus in most African societies, the parents, brothers and members of the community participate in the education of the younger ones. According to Fafunwa (1986) and Oroka (1990) every one in the society wants the child to grow up a conforming moral actor and a disciplined individual. The process of transmitting this value may include direct teaching by elders of what to do and correction by punishment when the child goes wrong; indirect method of benefiting from the experience of others through observation of how others behave and observation of how those who fail to conform to given norms are punished.

In the school system, rule and regulations are provided and enforced by teachers for the purpose of maintaining an effective discipline where teaching and learning can take place. There are also laid down procedures for punishing pupils who violates school rules. Unfortunately, it is sad to observe that the use of punishment had not in any way solved the problem of indiscipline among school pupils. One explanation to this effect is that by frequent punishment, the pupils soon becomes used to it. Against this background, Wood (1994) argues that punishment has a deterrent, though limited effects, beyond which it serve no useful purpose. For this reason he argues that punishment is no longer necessary and it has become inappropriate. It is therefore necessary for schools to go beyond this level of control to those that involve the information of opinion and social guidance. One approach is becoming popular amongst sociologists in the developed worlds is the sociotherapeutic technique which attempts a sociological diagnosis of any problem before attempting to control it.

\section{MATERIALS AND METHODS}

Technique of socio-therapy explained: The sociotherapeutic technique is related to Clinical Sociology. According to Freeman and Glassner (1999), it is the application of a variety of clinical applied practices which attempts a sociological diagnosis and treatment of group and group members in the community. So clinicians whether in medicine, psychology or sociology are professionals who interpret information obtained through research in their discipline for the purpose of diagnosis and therapy. Therapy itself consists of learning which alternative choices are more beneficial than a current state and acting to bring one or more of those choices to reality. This is exactly what the clinical psychologist does when he helps a patient reinterpret childhood, it is what the physician does when he prescribes antibiotic and it 
is what the sociologist does when he creates a peer self help group. In each case, the clinician uses the expertise from his or her own discipline along the client's own knowledge to decide which choices to pursue. Then the client must perform the acts necessary to pursue the new processes chosen.

Steps adopted in the socio-therapeutic approach: The steps usually adopted in the clinical sociological model have been explained by Okpilike (1994). The steps involve the following:

- Identification of a social problem e.g., truancy that is already affecting the students learning

- Identification of the possible social context (s) that must have given rise to the problem home background, neighborhood, community, peer group, school itself, etc.

- Diagnosing by discrimination among the various social forces or variables that accounted for the observed problem

- Application of appropriate actions which take into account the nature of the social problem

- Determination of the effectiveness of the social therapy by observing whether the incidence of the social identified in this case truancy had reduced. The steps are shown in Fig. 1

Major characteristics of the socio-therapeutic technique confidentiality: The purpose of any socio-therapeutic programme is to identify the problem that causes the individual or student to commit a particular offence (truancy in this case) and to help that student to overcome the problem. Because of this, the student must be assured that all interactions between him and the therapist (could be the teacher) is strictly confidential. Nothing said or done at the group or individual session would be brought to the knowledge of any other person except otherwise agree upon. They would also avoid talking to others about the therapy.

Interview with individual subject (student): Each student or individual in any socio-therapeutic programme must be interviewed on the information provided as factors that contribute to the problem. This information relate to family background, home addresses, occupation of parents, distance from school etc. The interview should usually be conducted between the individual and the therapist in a private place so chosen for that purpose. During the interview, agreement would be reached between on how the problems identified could be solved and whether or not any significant other is needed to solve the problem. When no other person is needed, the discussion ended with both.

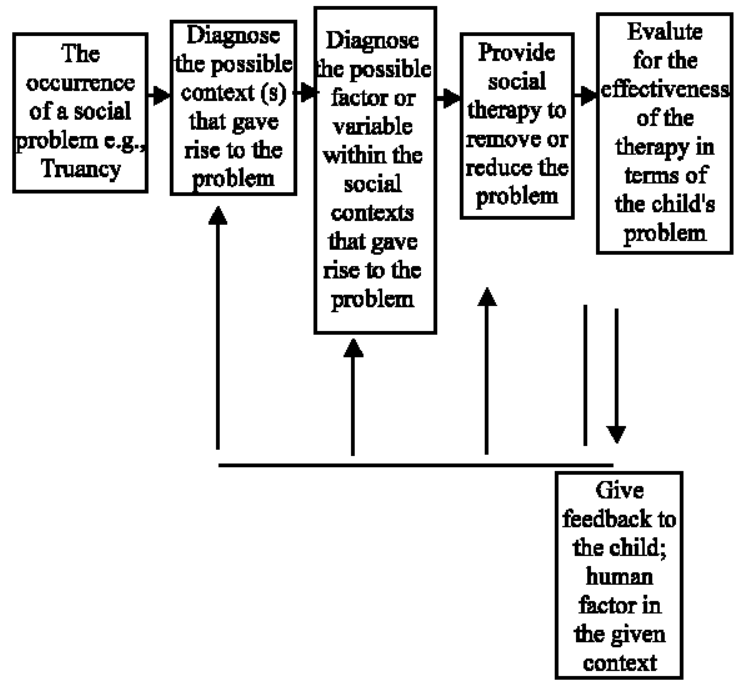

Fig. 1: Clinical sociology model of social therapy

Meeting with parents or guardian: Where the students problems could not be solved without reference to the parents or guardians of students a meeting with student's parents or guardian and the therapist becomes necessary. In such a case, the therapist has to the home of the student parents or guardian concerned. Most parents would indeed be happy that somebody (the therapist) has taken so much interest in the welfare of their child/ward. The problems facing the education of the child would now be outlined and discussed. The main achievement of this type of meeting is that a major agreement would be reached by all o how to improve the child's behavior pattern/school attendance in this case.

Parent Teachers Association meeting (PTA): Where the problems raised by parents could not be answered by the therapist, the parents/guardian would be requested to attend a meeting of the PTA, where such matters could be discussed. At the instance of the therapist, the principal of the school then summons a PTA meeting where all matters relating to the school (including) school attendance) could be discussed. During such meetings reference should be made to earlier discussion on the matter and all present are to contribute to resolving the problem. Parents are to return home to have further discussions with their children/wards on the outcome of the meeting.

Determining the effects of the socio-therapy: At the end of any socio-therapy, the therapist will systematically check whether there is a reduction in the incidence of the deviant act for which the therapy was conducted. If the incidence of the deviant act reduces, then the therapy can 
be said to have effective. The effectiveness of otherwise of the therapy can be determined by the therapist systematically observing whether there is improvement on the behavior pattern of students who received the therapy. Other teachers in the school can also assist in observing the pattern of school attendance by those students. Then a feed back on the result of the therapy would then be provided to the subjects themselves and to their parents and guardians. The process would be a continuous one depending on the behavior pattern of students and pupils in the school.

\section{RESULTS AND DISCUSSION}

It cannot be claimed for now that the sociotherapeutic technique will produce a panacea for all deviant cases among children in the school system. So far the evidence for treatment is inconsistent. Studies from other clinical evidences show that two major problems.

- Lack of specificity of ailment and of prescription

- Absence of patience desire to be cured affects the therapy

To this end, studies by Cressey (1998), Powers and Witner (2001), McCoard and McGinnes (1999) and Mullen and Dumpson (1972), offer a number of explanations for the negative evidence. These are that:

- The professional skill may not be applied

- The therapist may change during the programme

- The treatment may not continue long enough

Because of these lapses a more realistic position asserts that the limited but positive experimental evidence for the effect of therapy should be taken with considerable caution. However, the premises of social therapy is that one can gain a powerful perspective on the relationship between persons, groups, communities and societies; how they relate, interrelate and how they work for change through effective manipulation of these variables. To this end, man and his total environment are functioning wholes in nature with unique attribute that cannot understand by analysis of the parts alone. As by Tennenbaum (1998), it is clear that a deviant is a member of a group and the group and not the individual is the source of his problem.

This assertion agrees with Ezewu (1987) that the major assumptions underlying the clinical sociological approach to the solution of social problems are: that the people and material in each social setting in which the child interacts are capable of influencing his actions of others in the social setting. That the people and materials in each social setting in which the child interacts are capable of influencing his actions and he is also capable of influencing the actions of others in the social settings. It can therefore be agreed that the approach of clinical sociology is in line with the prescription for treatment for medical model which calls for knowledge of a specific treatment, skills, medicine or other prescription known to any of the various psychotherapeutic professions for treating deviant behavior. This means that in the absence of any specific known disease syndrome, one cannot treat that which is not known.

\section{CONCLUSION}

The technique of the socio-therapeutic approach to school discipline has not found expression in the present school system. Most teachers especially in the primary and secondary levels of education still believed that punishment remains the only means to enforce discipline. This account for the high rate of indiscipline among school children. There is the real need for all school teachers and administrators to familiarize themselves with a more human approach to deviant control. One easy way of doing this is to ensure that there is a proper and effective interaction among all stakeholders in the education industry.

\section{REFERENCES}

Cressey, D.R., 1998. The nature and effectiveness of correctional technique. Law Contemp. Prob., 23: 754-771.

Ezewu, E.E., 1987. The therapeutic effect of group activities of pupil Maladjustment in the classroom social system. Nigerian Journal of Education Psychology, Vol. 1.

Fafunwa, A.B., 1986. History of Education of Nigeria. G. Allen and Unwin Ltd., London.

Freeman, J. and B. Glassner, 1999. Clinical Sociology. Longmans, New York.

McCoard, L. and E. McGinnes, 1999. Social Behavior: A Functional Analysis. Houghton Co., Boston.

Mullen, E.J. and J.R. Dumpson, 1972. Evaluation of Social Intervention. Jossey-Bass, San Francisco, USA.

Okpilike, F.E.M., 1994. The theoritical framework of social therapy in clinical sociology. Delta Journal of Educational Development.

Oroka, O., 1990. The Philosophy of Educatiion: An Introduction. International Publishing Group, Ltd., London, New York.

Powers, E. and H. Witner, 2001. An Experiment in the Prevention of Delinquency. Columbia University Press, New York.

Tennenbaum, F., 1998. Crime and the Community. Ginn and Company, Boston.

Wood, A.L., 1994. Deviant Behaviour and Control Strategies. Lexington Books, London. 